\title{
Zur Kenntnis der tryptischen Verdauung des Leims. \\ Von
}

Th. Richard Krüger.

(Aus der chemischen Abteilung des physiologischen Instituts der Universität Leipzig.)

(Der Redaktion zugegangen am 18. April 1903.)

Auf Veranlassung des Herrn Prof. Siegfried bin ich mit der Untersuchung der durch tryptische Verdauung aus Gelatine entstehenden Peptone beschäftigt. Diese Peptone sind, ebenso wie die bisher bekannten, durch Enzyme aus Proteinkörpern entstehenden ausgesprochene Säuren, die auf Lackmus intensiv sauer reagieren und mit Carbonaten unter Austreibung der Kohlensäure Salze bilden.

Das zunächst untersuchte Trypsin-Glutinpepton $\beta$ ist von der chemischen Fabrik von Heyden genau nach Siegfrieds Vorschriften dargestellt.

Trypsin-Glutinpepton $\beta$ (aus I. Eisenniederschlage).

Die Substanzen wurden zur Analyse bei $70^{\circ}$ b. z. c. G. getrocknet.

\section{Präparat I.}

1. $0,2378 \mathrm{~g}$ Substanz gaben $0,1402 \mathrm{~g} \mathrm{H}_{2} \mathrm{O}$ und $0,4084 \mathrm{~g} \mathrm{CO}_{2}$.

2. $0,2245 \gg \gg \quad 33,3 \mathrm{ccm}$ bei $18,5^{\circ}$ und $755 \mathrm{~mm}$ Bar.

$$
\text { Präparat II. }
$$

3. $0,2100 \mathrm{~g}$ Substanz gaben $31,6 \mathrm{ccm} \mathrm{N}$ bei $18^{\circ}$ und $754 \mathrm{~mm}$ Bar.

$4.0,2492$ > > > 36,6 > > $17^{\circ}$ > 755 , >

5. 0,2600 > > $0,1486 \mathrm{~g} \mathrm{H}_{2} \mathrm{O}$ und $0,4466 \mathrm{~g} \mathrm{CO}_{2}$.

Dasselbe umgefällt:

6. $0,2326 \mathrm{~g}$ Substanz gaben $35,6 \mathrm{ccm} \mathrm{N}$ bei $19,5^{\circ}$ und $748 \mathrm{~mm}$ Bar.

$7.0,2310>>34,3>>>18,5^{\circ}>755$,

$8.0,1750$ > > $>0,0902 \mathrm{~g} \mathrm{H}_{2} \mathrm{O}$ und $0,2988 \mathrm{~g} \mathrm{CO}_{2}$ ». 
Zur Kenntnis der tryptischen Verdauung des Leims.

\begin{tabular}{c|c|c|c|c|c|c|c|c|c}
\hline \hline$\%$ & 1 & 2 & 3 & 4 & 5 & 6 & 7 & 8 & $\begin{array}{r}\text { Berechnet } \\
\%\end{array}$ \\
\hline $\mathrm{C}$ & 46,80 & - & - & - & 46,85 & - & - & 46,57 & 46,86 \\
$\mathrm{H}$ & 6,55 & - & - & - & 6,34 & - & - & 5,72 & $\begin{array}{r}6,23 \\
\mathrm{~N}\end{array}$ \\
\hline & 17,26 & 17,51 & 17,17 & - & 17,58 & 17,27 & - & 17,32
\end{tabular}

Aus diesen Zahlen berechnet sich die Formel:

$$
\mathbf{C}_{19} \mathbf{H}_{30} \mathbf{N}_{8} \mathbf{0}_{9} \text {. }
$$

Auf diese Formel bezogen ist das Pepton eine einbasische Säure, wie folgende Bestimmungen zeigen:

1. Zinksalz aus Präparat I, aus der wässerigen Lösung durch Alkohol gefältt.

0,2441 g Substanz gaben 0,0191 g Zn0.

2. Zinksalz aus Präparat $I$, die wässerige Lösung eingedampft.

0,3212 g Substanz gaben 0,0262 g ZnO.

3. Barytsalz aus Präparat lI, eingedampft.

$0,7218 \mathrm{~g}$ Substanz gaben 0,1438 $\mathrm{g} \mathrm{BaSO}_{4}$.

4. Barytsalz aus umgefälltem Präparat II, mit Alkohol gefällt.

$0,4722 \mathrm{~g}$ Substanz gaben $0,1000 \mathrm{~g} \mathrm{BaSO}_{4}$.

5. Zinksalz desselben Präparates.

0,2088 g Substanz gaben 0,0160 g Zn0.

Gefunden:

Berechnet:

$\begin{array}{rrrrr}\mathrm{Zn} & \text { 1. } 6,28 \% & \text { 2. } 6,55 \% & \text { 5. } 6,15 \% . & 6,30 \% . \\ \mathrm{Ba} & \text { 3. } 11,77 \% & \text { 4. } 12,45 \% & & \\ \end{array}$

Die Molekulargewichtsbestimmungen mit Hilfe der Bestimmung der Gefrierpunktserniedrigung in wässeriger Lösung ergaben auch für dieses Pepton keine scharfen Werte. Für Präparat II umgefällt wurde gefunden: $866 ; 946 ; 903$. Die doppelte Größe der angegebenen Formel verlangt 973.

Die Einheitlichkeit des Peptons wird am schärfsten durch die Konstanz der optischen Aktivität beim Umfällen, bei dem jedesmal ein wesentlicher Teil der Substanz in Lösung bleibt, bewiesen.

In den folgenden Bestimmungen wurde teils die abgewogene Substanz im Maßkölbchen aufgelöst, teils wurde durch Eindampfen der polarisierten Lösung und Wägen des bei $70^{\circ}$ b. z. c. G. getrockneten Rückstandes die Konzentration ermittelt. 


\section{Präparat II.}

1. $\alpha=-3,44^{\circ}, \quad \mathrm{c}=3,4290, \quad \mathrm{l}=1, \mathrm{t}=20^{\circ}$.

$[\alpha]_{D}^{20^{\circ}}=-100,0^{\circ}$.

Dasselbe Pepton, umgefällt.

2. $\alpha=-4,16^{\circ}, \mathrm{c}=2,010, \quad \mathrm{l}=2, \mathrm{t}=20^{\circ}$.

$[\alpha]_{D}^{20^{\circ}}=-103,4^{\circ}$.

Dasselbe Pepton, 2 mal umgefällt.

3. $\alpha=-4,13^{\circ}, \quad \mathrm{c}=2,050, \quad \mathrm{l}=2, \mathrm{t}=20^{\circ}$.

$[\alpha]_{\mathrm{D}}^{20^{\circ}}=-100,75^{\circ}$.

Dasselbe Pepton, 3 mal umgefällt.

4. $\alpha=-5,38^{\circ}, \mathrm{c}=2,7150, \quad \mathrm{l}=2, \mathrm{t}=20^{\circ}$.

$$
[\alpha]_{\mathrm{D}}^{20^{0}}=-99,1^{\circ}
$$

Das Trypsin-Glutinpepton $\beta$. besitzt also für $2-3,5 \%$ ige Lösungen das spezifische Drehungsvermögen

$$
[\alpha]_{D}^{200}=-100,8^{\circ}
$$

Das einmal umgefällte Pepton enthielt $0,17 \% \mathrm{~S}$.

$1,5683 \mathrm{~g}$ Substanz gaben $0,0208 \mathrm{~g} \mathrm{BaSO}_{4}=0,17 \% \mathrm{~S}$.

Die Reaktionen dieses Peptons sind dieselben wie die der Trypsin-Fibrinpeptone, die Millonsche und Molischsche Reaktion war ebenfalls völlig negativ.

Neben diesem Pepton entstehen bei der tryptischen Verdauung des Leims noch ein oder mehrere andere Peptone. $\mathrm{Zu}$ deren Isolierung habe ich mehrmals $500 \mathrm{~g}$ Gelatine verdaut und die aus dem zweiten Eisenniederschlage gewonnenen Produkte untersucht. Es gelang jedoch bis jetzt nicht, zu sicheren Resultaten zu gelangen. Bei den fortgesetzten Umfällungen wurden Produkte nicht ganz konstanter Zusammensetzung und Äquivalenz erhalten, vor allem differierte die optische Aktivität der einzelnen Fraktionen nicht unbeträchtlich. Schließlich wurden allerdings aus 2 Parallellösungen 2 Präparate gewonnen, die die gleiche Zusammensetzung und die übereinstimmende optische Aktivität $[\alpha]_{D}^{200}=-64,4^{\circ}$ und $-64,2^{\circ}$ besaßen. Zusammensetzung und Größe des Äquivalentgewichtes führten $\mathrm{zu}$ der Formel $\mathrm{C}_{15} \mathrm{H}_{23} \mathrm{~N}_{5} \mathrm{O}_{8}$, die ich aber nur mit Reserve angeben möchte. Durch die häufigen Umfällungen war leider das Material verbraucht, sodaß die Umfällungen vorläufig nicht weiter geführt werden konnten. 